\title{
Effect of Oxygen Content in Atmospheres of Heat Treatment on the Properties of YBCO Thin films
}

\author{
Wu Chuanbao', Zhao Gaoyang1, $\quad$ Fang Po', Lei Li ${ }^{1}, \quad$ Li Chengshan ${ }^{2}$ \\ ${ }^{1}$ Xi'an University of Technology, Xi'an 710048, China; ${ }^{2}$ Northwest Institute for Non-ferrous Metal Research, Xi'an 710016, China
}

\begin{abstract}
YBa}_{2} \mathrm{Cu}_{3} \mathrm{O}_{7-x}(\mathrm{YBCO})$ films were prepared on single-crystal $\mathrm{LaAlO}_{3}(100)$ substrate using a low-fluorine sol-gel method. The effect of the oxygen content in the atmospheres of heat treatment at $725{ }^{\circ} \mathrm{C}$ on the critical current density $\left(J_{\mathrm{c}}\right)$ of the obtained YBCO films was investigated. Results show that all the films heat-treated in the oxygen content range of 100 1700 $\mu \mathrm{L} / \mathrm{L}$ exhibit good biaxial-texture characteristics. However, high- $J_{\mathrm{c}}$ YBCO films are not obtained at the oxygen contents of 100 and $200 \mu \mathrm{L} / \mathrm{L}$ due to the lower density of the surfaces. With increasing the oxygen content, the film surface becomes dense gradually. When the oxygen content is $300 \mu \mathrm{L} / \mathrm{L}$, the surface of the film is very dense and $J_{\mathrm{c}}$ reaches $4.3 \mathrm{MA} / \mathrm{cm}^{2}$. Furthermore, many copper-rich second phases grow up on the surfaces with further increasing oxygen content up to 800 and $1700 \mu \mathrm{L} / \mathrm{L}$, which is a dominant reason for the decline in $J_{\mathrm{c}}$ of the films.
\end{abstract}

Key words: superconducting film; sol-gel; low-temperature heat treatment; texture; oxygen content

The fluorine-contained sol-gel method is an attractive candidate for preparing $\mathrm{YBa}_{2} \mathrm{Cu}_{3} \mathrm{O}_{7-x} \quad$ (YBCO) superconducting films or coated conductors because the method is of high repeatability in fabricating YBCO films with excellent superconducting properties $\left(T_{\mathrm{c}}>91 \mathrm{~K}, J_{\mathrm{c}}>1\right.$ $\left.\mathrm{MA} / \mathrm{cm}^{2}\right)^{[1,2]}$. Regarding the numerous superconducting thin film architectures for practical applications, such as the multilayer structure in superconducting electronics and the coated conductor on a buffered metal substrate tape, it is desirable to fabricate YBCO films on an insulating or conducting barrier layer ${ }^{[3-5]}$. Currently, the common heat-treatment temperature for YBCO films derived from the sol-gel method is around $800{ }^{\circ} \mathrm{C}{ }^{[6,7]}$. At such high temperature, the interdiffusion between the barrier layer and the YBCO film is probable, which will deteriorate the superconductivity dramatically. Thus, a low-temperature heat treatment is required ${ }^{[8]}$. The Araki group fabricated superconducting YBCO film at the heat-treatment temperature of $725^{\circ} \mathrm{C}{ }^{[9]}$; however, the effect of the growth parameters at $725^{\circ} \mathrm{C}$ on the characteristics of YBCO film is scarce.
Hammond and Bormann ${ }^{[10]}$ produced an oxygen partial pressure-temperature $\left(P_{\mathrm{O}_{2}}-T\right)$ phase diagram according to various in-situ deposition experiments; the diagram revealed that the forming temperature $(T)$ of YBCO film could be decreased by lowering the oxygen partial pressure $P_{\mathrm{O}_{2}}$ in the growing environment. However, the $P_{\mathrm{O}_{2}}-T$ relationship derived from the ex-situ process of electron-beam co-evaporation $\left(\mathrm{BaF}_{2}\right.$ process $)$ deviates from the in-situ deposition line ${ }^{[11]}$. Due to the lack of experimental data, whether the $P_{\mathrm{O}_{2}}-T$ relationship of a sol-derived YBCO film heated at a relatively low temperature follows the in-situ or the ex-situ deposition line remains undetermined. Furthermore, in our previous research an advanced low-fluorine sol-gel method was proposed for preparing high- $J_{\mathrm{c}}$ YBCO film ${ }^{[12]}$, in which the pyrolysis time was shortened drastically due to the reduction of fluorine greatly in the precursor solution. In the present paper, based on the low-fluorine sol-gel method, the oxygen content during heat treatment at $725{ }^{\circ} \mathrm{C}$ was explored in order to obtain high $-J_{\mathrm{c}}$ YBCO films at a low heat-treatment temperature.

Received date: August 07, 2015

Foundation item: National Natural Science Foundation of China (51372198); Doctorial Innovation Foundation of Xi'an University of Technology (310-11202j403) Corresponding author: Zhao Gaoyang, Professor, Department of Materials Physics and Chemistry, Xi'an University of Technology, Xi'an 710048, P. R. China, E-mail: zhaogy@xaut.edu.cn 


\section{Experiment}

The precursor solution of YBCO films was obtained by dissolving fluorine-contained yttrium, non-fluorine barium, and non-fluorine copper acetate salts into methanol with the help of acrylic $\operatorname{acid}^{[12]}$. The total metallic ion concentration of the synthesized precursor solution was $1.2 \mathrm{~mol} / \mathrm{L}$. With a single crystal $\mathrm{LaAlO}_{3}$ (100) as a substrate, all of the dip-coated gel films were pyrolysised at $450{ }^{\circ} \mathrm{C}$ in the same batch. Moisture was introduced by bubbling deionized water with the dew-point temperature of $40{ }^{\circ} \mathrm{C}$. The whole heat-treatment profile is shown in Fig.1. After the pyrolysis, many nanocrystallines of the metal fluoride and oxide formed. In order to avoid growing up of the nanocrystallines, the pyrolysed film must be cooled down to at least $200{ }^{\circ} \mathrm{C}$ rapidly. After that, the gas was switched to the mixed gas of nitrogen and oxygen with different $\mathrm{O}_{2} / \mathrm{N}_{2}$ ratios. The flow rates of nitrogen and oxygen were controlled by a precision mass flowmeter, which enabled an oxygen content of $100 \sim 1700 \mu \mathrm{L} / \mathrm{L}$ to be achieved. Then, the samples were heated to $725{ }^{\circ} \mathrm{C}$ for $100 \mathrm{~min}$ in the mixed gas with different oxygen contents. After that, all of the films were oxygenated at $450{ }^{\circ} \mathrm{C}$ for $2 \mathrm{~h}$ in the same batch, which transformed the YBCO into an orthogonal structure with superconducting properties.

The thicknesses of all of the YBCO films were measured by a Surfcorder-SE3500 surface profiler, and the results indicated that all the film thicknesses were approximately $200 \mathrm{~nm}$ due to the use of the same solution and withdrawal rate. A SmartLab X-ray diffractometer in $\theta-2 \theta, \omega$, and $\varphi$ scan modes was used to determine the film phase, the out-of-plane and in-plane texture, respectively. Scanning electron microscopy (SEM) experiments were performed on a Merlin Compact after depositing conductive Pt onto the surface of the films. A VersaLab multi-function vibrating sample magnetometer was used to measure the magnetic moment $m$ under a

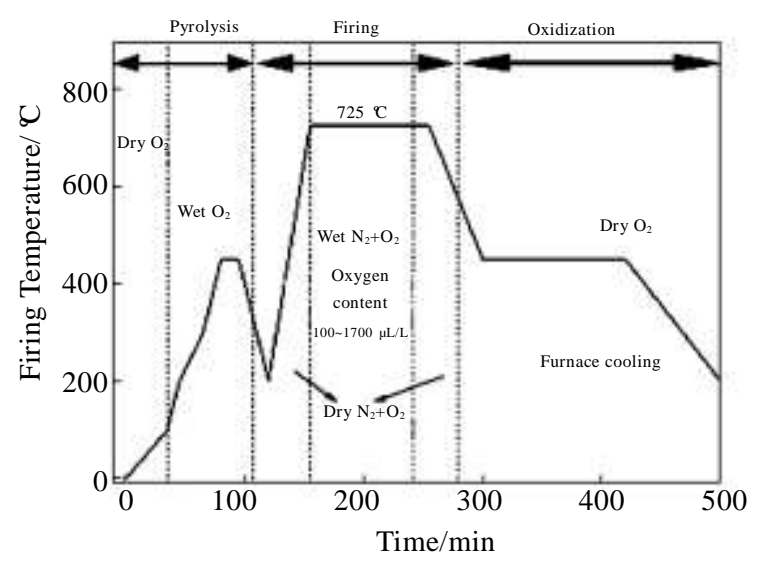

Fig.1 Profile of the heat treatment for preparing YBCO films varying magnetic field, and then, $J_{\mathrm{c}}$ was calculated using the extended Bean model, as given by Eq. $(1)^{[13]}$ :

$$
J_{\mathrm{c}}=20 \Delta m /[\mathrm{Va}(1-a / 3 b)]
$$

Where $\Delta m$ is the vertical width in the $m-B$ loop in a certain field and $V, a$ and $b(a<b)$ are the volume, the width and length of the samples, respectively. The size of the films used in the magnetization measurement was $2.5 \mathrm{~mm} \times 3.0 \mathrm{~mm}$. The temperature was fixed at $77 \mathrm{~K}$, and the applied field with magnetic strength of $0 \sim 3 \mathrm{~T}$ was perpendicular to the film surface during the measurement.

\section{Results and Discussion}

\section{$2.1 J_{\mathrm{c}}$ of YBCO film}

Fig.2 shows the dependence of critical current density $\left(J_{c}\right)$ of YBCO films on the magnetic field $B$. It can be seen that the $J_{c}$ of the film in the entire applied field range of 1 3 $\mathrm{T}$ increases at first and then decreases with raising the oxygen content from 100 to $1700 \mu \mathrm{L} / \mathrm{L}$. When the oxygen content is $300 \mu \mathrm{L} / \mathrm{L}, J_{\mathrm{c}}$ of the YBCO film reaches $4.3 \mathrm{MA} / \mathrm{cm}^{2}$. The $J_{\mathrm{c}}$ value is larger than that reported by Araki group ${ }^{[9]}$, which could be correlated with the larger oxygen content adopted in this study. The oxygen content of $300 \mu \mathrm{L} / \mathrm{L}$ can be converted to the oxygen partial pressure of about $30 \mathrm{~Pa}$ according to the total gas pressure close to $10^{5} \mathrm{~Pa}$. The heat-treatment parameter of $725^{\circ} \mathrm{C} / 30 \mathrm{~Pa}$ is just on the thermodynamic equilibrium line corresponding to the tetragonal phase $\mathrm{YBa}_{2} \mathrm{Cu}_{3} \mathrm{O}_{6.09}$ (it is not the final composition, which is just one after heat treatment without further oxidation) in $\log P_{\mathrm{O}_{2}}-1000 / T$ diagram $^{[11,14,15]}$. Commonly, $J_{\mathrm{c}}$ of YBCO film is relatively high when the heat-treatment parameters on the thermodynamic equilibrium line are adopted. Therefore, the $725{ }^{\circ} \mathrm{C} / 300 \mu \mathrm{L} / \mathrm{L}$ could be considered as alternative parameters for fabricating high- $J_{\mathrm{c}}$ YBCO film at $725{ }^{\circ} \mathrm{C}$.

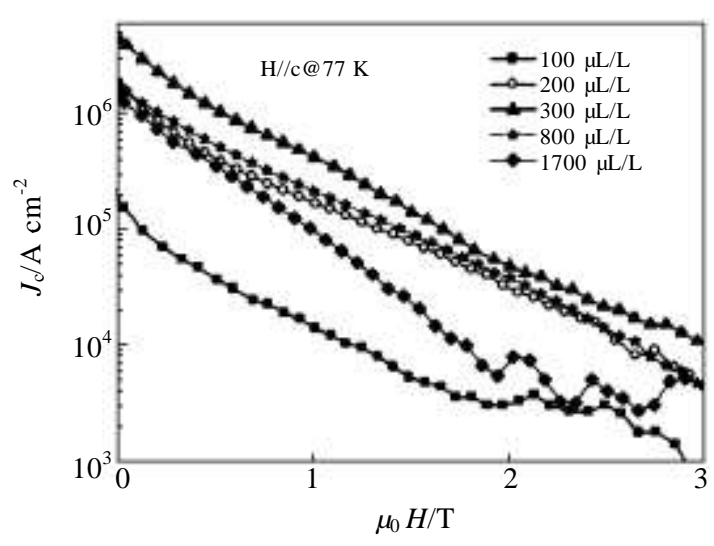

Fig.2 $J_{\mathrm{c}}-B$ relationship of YBCO films heat-treated under different oxygen contents 


\subsection{Reasons for the change of $J_{c}$ with the oxygen content during heat treatment}

It is well known that the purity and biaxial texture of YBCO film are important factors on the $J_{\mathrm{c}}$ of the film. In order to explore the reasons for the change of $J_{\mathrm{c}}$ with the oxygen content during heat treatment, $\theta-2 \theta$ scans of $\mathrm{X}$-ray diffraction were carried out on the films and the results are shown in Fig.3. It is seen that apart from the diffraction peaks of the substrate and YBCO $(00 l)$, nearly no peaks due to other phases or non- $c$-axis-oriented YBCO were detected, indicating that the YBCO films exhibit good purity and $c$-axis-preferred orientation.

To evaluate the out-of-plane and in-plane orientation, $\omega$ and $\Phi$ scans of X-ray diffraction were conducted on the crystal planes (005) and (103) of the YBCO films, respectively. The dependence of the calculated full width at half maximum (FWHM) values of $\omega$ - and $\Phi$ scans on the oxygen content is shown in Fig.4. It is found that FWHM values of $\omega$ - and $\Phi$ scans are relatively large under the oxygen contents of 100 and $200 \mu \mathrm{L} / \mathrm{L}$, while FWHM values become lower at $300 \mu \mathrm{L} / \mathrm{L}$ and tend to be uniform with further increasing the oxygen content. According to Ref.[10], the driving force for nucleation is weak under tiny oxygen content, leading to relatively less formation of YBCO grains and thereby to relatively weak diffraction peaks and large FWHM values. However, the FWHM values of $\omega$ - and $\Phi$ scans fall in the scale of $0.5^{\circ} \sim 0.9^{\circ}$ and $1.4^{\circ} \sim 2.3^{\circ}$, respectively. Such small-scale variation in FWHM values are not enough to change $J_{\mathrm{c}}$ obviously, so the variation of $J_{\mathrm{c}}$ is likely to be relative to other factors such as the surface morphology.

Surface quality is also a significant factor on $J_{\mathrm{c}}$ of YBCO film. Thus, surface morphologies of YBCO films were examined, which is shown in Fig.5. It is seen that many pores appear on the surface of YBCO film when

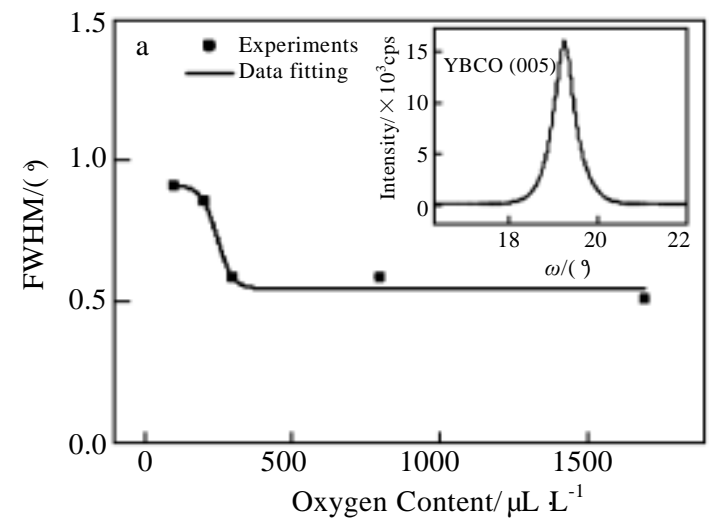

the oxygen content is $100 \mu \mathrm{L} / \mathrm{L}$, which is responsible for the lower $J_{\mathrm{c}}$. In this case, the driving force is not enough to form uniform YBCO films due to the too-low oxygen content $^{[10]}$. With increasing the oxygen content, the film surface becomes denser. When the oxygen content is 300 $\mu \mathrm{L} / \mathrm{L}$, the surface is very dense, resulting in the enhancement of $J_{\mathrm{c}}$. However, with further increasing the oxygen content up to 800 and $1700 \mu \mathrm{L} / \mathrm{L}$, several large particles form on the film surface. By the energy dispersive spectroscopy (EDS) analysis, the large particles are proved to be copper-rich phases. According to the Ref.[10], high oxygen content allows for cluster formation of metal oxides on the surface due to the enhancement of the driving force for nucleation. Therefore, many copper-rich particles appear on the film surface. These copper-rich phases are likely to induce the deviation of film composition at localized areas, thereby leading to decline of $J_{\mathrm{c}}$.

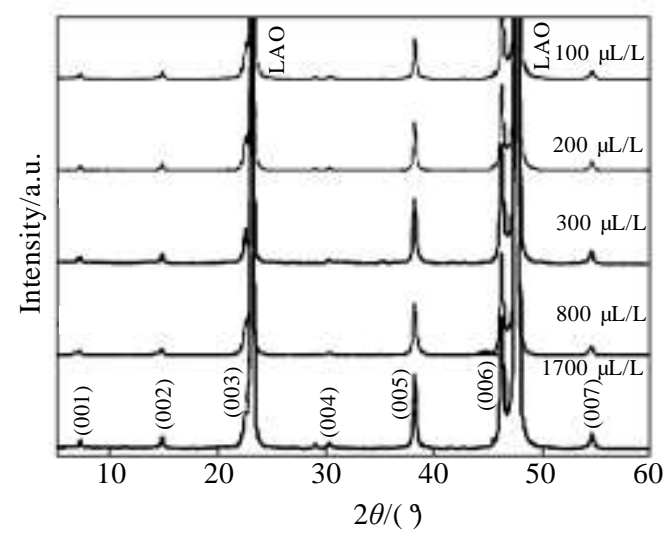

Fig.3 $\theta-2 \theta$ scan of XRD for YBCO films heat-treated under different oxygen contents

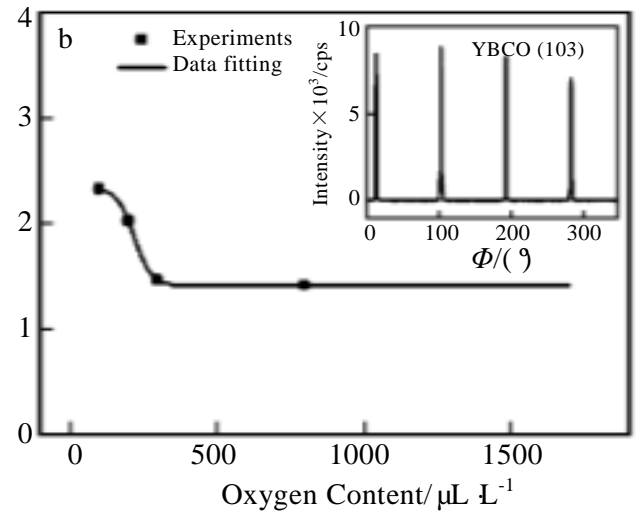

Fig.4 FWHM dependence of $\omega$ - (a) and $\Phi$ (b) scans on the oxygen content during heat treatment for YBCO films. (the insets are original results of $\omega$ - and $\Phi$ scans for the sample heat-treated at the oxygen content of $300 \mu \mathrm{L} / \mathrm{L}$ ) 


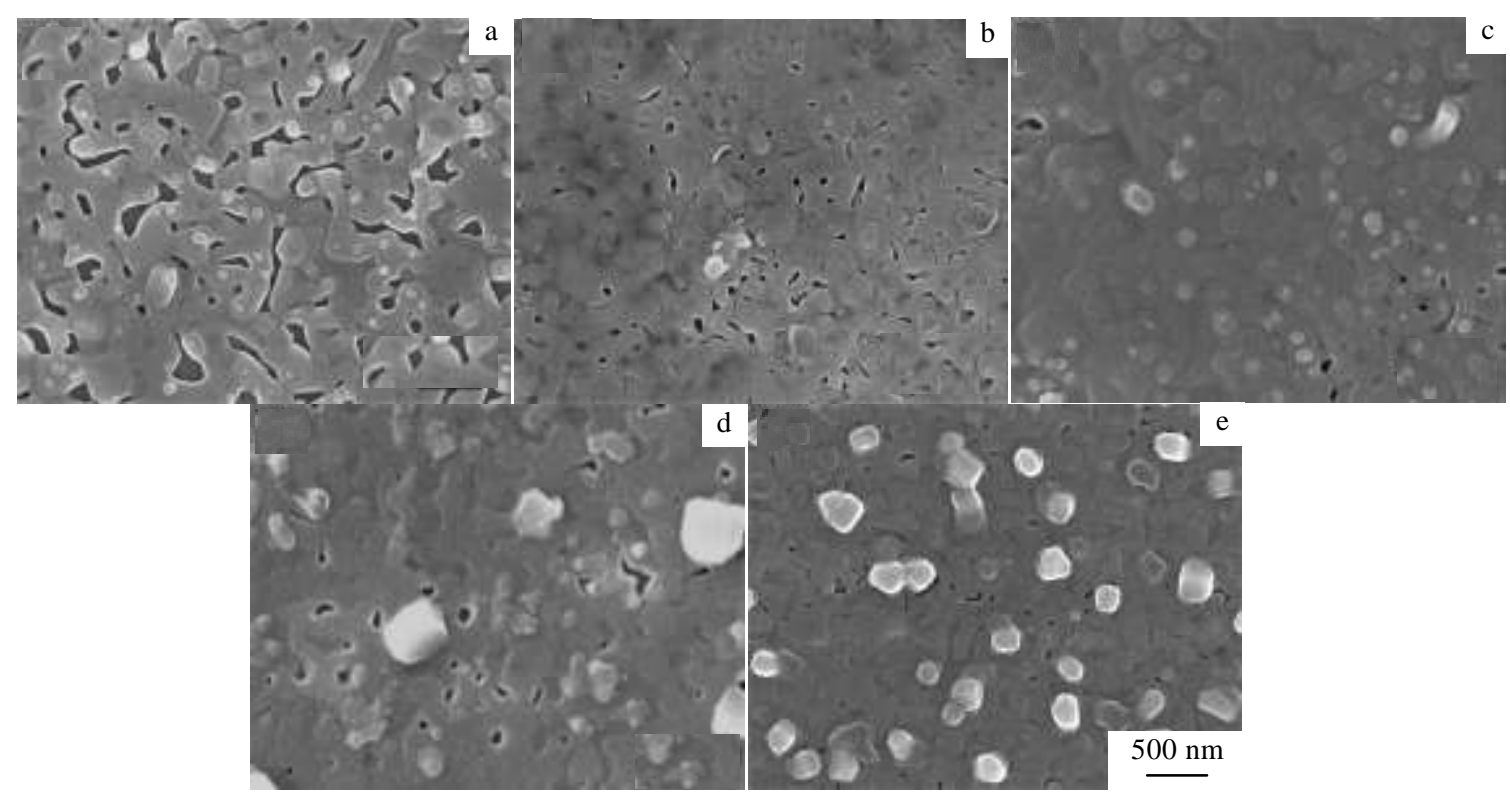

Fig.5 Surface morphologies of YBCO films heat-treated at the oxygen contents of $100 \mu \mathrm{L} / \mathrm{L}$ (a), $200 \mu \mathrm{L} / \mathrm{L}$ (b), $300 \mu \mathrm{L} / \mathrm{L}$ (c), $800 \mu \mathrm{L} / \mathrm{L}$ (d), and $1700 \mu \mathrm{L} / \mathrm{L}$ (e)

\section{Conclusions}

1) The surface of YBCO film becomes denser with increasing the oxygen content in the range of 100 1700 $\mu \mathrm{L} / \mathrm{L}$, but copper-rich second phases grow up gradually.

2) When the oxygen content is $300 \mu \mathrm{L} / \mathrm{L}$, the YBCO film exhibits good density, only a few second-phase particles appear on the surface, and $J_{\mathrm{c}}$ reaches $4.3 \mathrm{MA} / \mathrm{cm}^{2}$.

\section{References}

1 Araki T, Yamagiwa K, Hirabayashi I et al. Superconductor Science \& Technology[J], 2001, 14: L21

2 Nakaoka K, Yoshizumi M, Usui Y et al. IEEE Transactions on Applied Superconductivity[J], 2013, 23(3): 6600404

3 Hunt B D, Forrester M G, Talvacchio J et al. Applied Physics Letters[J], 1996, 68(26): 3805

4 Obradors X, Puig T. Superconductor Science \& Technology[J], 2014, 27: 044003

5 Paranthaman M P, Qiu X, List F A et al. IEEE Transactions on Applied Superconductivity[J], 2011, 21(3): 3059
6 Obradors X, Puig T, Pomar A et al. Superconductor Science \& Technology[J], 2004, 17: 1055

7 Zhao G Y, Chen Y Q, Lei L et al. IEEE Transactions on Applied Superconductivity[J], 2007, 17(1): 40

8 Araki T, Takahashi Y, Yamagiwa K et al. Physica C[J], 2001, 357-360: 991

9 Araki T, Takahashi Y, Yamagiwa K et al. IEEE Transactions on Applied Superconductivity [J], 2001, 11(1): 2869

10 Hammond R H, Bormann R. Physica C[J], 1989, 162-164: 703

11 Feenstra R, Lindemer T B, Budai J D et al. Journal of Applied Physics[J], 1991, 69(9): 6569

12 Chen Y Q, Wu C B, Zhao G Y et al. Superconductor Science \& Technology[J], 2012, 25: 062001

13 Gyorgy E M, Van Dover R B, Jackson K A et al. Applied Physics Letters[J], 1989, 55: 283

14 Lindemer T B, Hunley J F, Gates J E et al. Journal of the American Ceramic Society[J], 1989, 72(10): 1775

15 Wu C B, Zhao G Y, Fang P. Materials Chemistry and Physics[J], 2015, 167: 160 


\title{
热处理气氛中氧含量对 YBCO 薄膜性能的影响
}

\author{
武传宝 ${ }^{1}$, 赵高扬 ${ }^{1}$, 房 坡 ${ }^{1}$, 雷 黎 $^{1}$, 李成山 ${ }^{2}$ \\ (1. 西安理工大学, 陕西 西安 710048) \\ (2. 西北有色金属研究院, 陕西 西安 710016)
}

\begin{abstract}
摘 要: 采用低氟溶胶-凝胶法在 $\mathrm{LaAlO}_{3}(100)$ 基板上制备了 $\mathrm{YBa}_{2} \mathrm{Cu}_{3} \mathrm{O}_{7-x}(\mathrm{YBCO})$ 薄膜, 研究了在 $725{ }^{\circ} \mathrm{C}$ 热处理过程中, 氧含量对最终所 得YBCO薄膜临界电流密度 $J_{\mathrm{c}}$ 的影响。研究发现, 热处理过程中氧气含量在 $100 \sim 1700 \mu \mathrm{L} / \mathrm{L}$ 范围变化时, 所获得的YBCO薄膜均具有良好 的双轴织构特征。然而, 当氧气含量为 100 或 $200 \mu \mathrm{L} / \mathrm{L}$ 时, 由于 $Y B C O$ 薄膜致密性差, 不能获得高 $J_{\mathrm{c}}$ 的 $\mathrm{YBCO}$ 薄膜。随着氧气含量的增大, $\mathrm{YBCO}$ 薄膜表面逐渐变得致密。当氧气含量增加到 $300 \mu \mathrm{L} / \mathrm{L}$ 时, $\mathrm{YBCO}$ 薄膜表面较致密, $J_{\mathrm{c}}$ 达到 $4.3 \mathrm{MA} / \mathrm{cm}^{2}$ 。继续增大氧含量至 800 和 1700 $\mu \mathrm{L} / \mathrm{L}$, 薄膜表面逐渐出现富铜第二相颗粒, 成为其 $J_{\mathrm{c}}$ 较低的主要原因。
\end{abstract}

关键词：超导薄膜; 溶胶-凝胶; 低温热处理; 织构; 氧含量

作者简介：武传宝, 男, 1986 年生, 博士生, 西安理工大学材料学院, 陕西西安 710048, 电话: 029-82312172, E-mail: wuchuanbao015@163.com 